
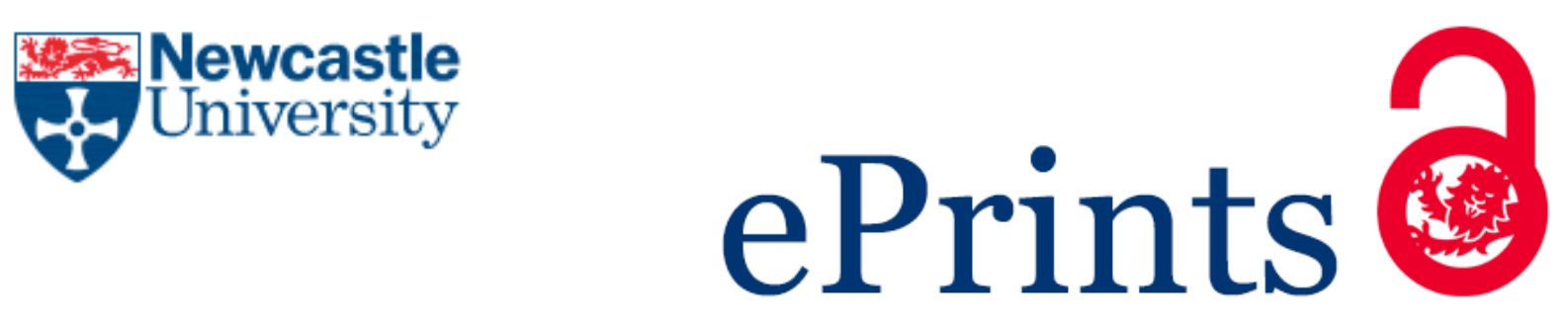

\author{
Martin P, Newton A, Pfeifer M, Khoo M, Bullock JM. \\ Impacts of tropical selective logging on carbon storage and tree species \\ richness: A meta-analysis. \\ Forest Ecology and Management 2015, 356, 224-233
}

\title{
Copyright:
}

(C) 2015. This manuscript version is made available under the CC-BY-NC-ND 4.0 license

DOI link to article:

http://dx.doi.org/10.1016/j.foreco.2015.07.010

Date deposited:

$11 / 05 / 2016$

Embargo release date:

21 July 2016

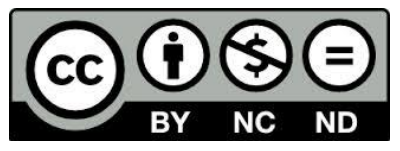

This work is licensed under a

Creative Commons Attribution-NonCommercial-NoDerivatives 4.0 International licence 


\section{Impacts of tropical selective logging on carbon storage and tree}

2 species richness: a meta-analysis

4 Philip A Martin ${ }^{1,2}$, Adrian C.Newton ${ }^{2}$, Marion Pfeifer ${ }^{3}$, MinSheng Khoo ${ }^{3}$, and James M.

5 Bullock $^{1}$

6

$7 \quad{ }^{1}$ Centre for Ecology and Hydrology, Benson Lane, Wallingford, Oxfordshire. OX10 8BB. UK.

$8{ }^{2}$ Centre for Conservation, Ecology and Environmental Science, Faculty of Science and Technology,

9 Bournemouth University, Poole, BH12 5BB, UK.

$10{ }^{3}$ Forest Ecology and Conservation Research Group, Imperial College London, Silwood Park,

11 Buckhurst Road, Ascot, Berkshire, SL5 7PY. UK

13 Keywords: deforestation, degradation, land-use, REDD+, RIL, selective logging, biomass

15 Corresponding author email: martinp@bournemouth.ac.uk 


\section{Abstract}

19 Over 400 million hectares of tropical forest are currently designated as logging concessions. This practice is an important source of timber, but there are concerns about its long-term sustainability and impacts on biodiversity and carbon storage. However, logging impacts vary widely, making generalisation and, consequently, policy implementation, difficult. Recent syntheses of animal

23 biodiversity have indicated that differences in logging intensity - the volume of wood removed ha ${ }^{-1}$

24 - might help to explain some of these disparities. In addition, it has widely been assumed that 25 reduced impact logging (RIL) might minimise some of the negative effects of logging; though in practice, this has rarely been tested. To test the hypothesis that RIL reduces negative impacts of selective logging once intensity is controlled for, we used meta-analyses of selective logging impact studies, focusing specifically on (1) residual tree damage, (2) aboveground biomass and (3) tree species richness. Our results indicate that RIL appears to reduce residual tree damage when compared to conventional methods. However, changes in aboveground biomass were negatively related to logging intensity. Any effect of RIL, independent of logging intensity, was difficult to discern since it was carried out at relatively low intensities. Tree richness appeared to increase at low intensities but decreased at higher intensities and any effect of RIL was difficult to detect. Our results tentatively support the hypothesis that RIL reduces the negative impacts of logging on tree damage, but do not support suggestions that RIL reduces loss of aboveground biomass or tree species richness. However, this lack of support may be a result of the relative paucity of data on the topic. Based on our results, we suggest that better evidence is needed to assess the differences between the impacts of RIL and conventional logging. Studies that consider plot-level differences in logging intensity are required to fill this knowledge gap. In addition, there must be clarification of whether RIL is an inherently low intensity practice so that this can be factored into management. 
Over 400 million hectares of tropical forest are designated as timber concessions, making selective logging - the removal of selected trees from a stand - one of the most widespread human disturbances in tropical forests (Asner et al., 2009). Tropical logging produces approximately one eighth of global timber (Blaser et al., 2011), and is an important contributor to many local and national economies. However, logging can have negative impacts on biodiversity (Berry et al., 2010) and leads to increased carbon emissions (Bryan et al., 2010; Nepstad et al., 1999). Poor management of logging concessions can endanger the long-term sustainability of timber production and there have been suggestions that we might be approaching peak timber production in the tropics (Shearman et al., 2012).

Given the large global demand for tropical timber, researchers have proposed modifications to logging techniques to reduce their negative environmental effects, particularly regarding carbon emissions (Putz et al., 2008b) and their impacts on biodiversity (Bicknell et al., 2015). The direct impacts of selective logging are largely the result of the effects of harvesting, skidding of logs, and construction of infrastructure, such as roads, on the mortality and recruitment of trees. The major source of carbon losses is the felling of large trees. However, damage and subsequent death of smaller trees as a result of crushing by felled trees or damage during removal of logs can also be a major contributor of carbon emissions (Putz et al., 2008b). Damage and mortality of non-target trees can also limit forest recovery (Gourlet-Fleury et al., 2013b; Sist et al., 2014) and, if recruitment fails to keep pace with mortality, this can result in altered tree community composition (Ouédraogo et al., 2011). Some of the negative effects of logging on carbon emissions and biodiversity could potentially be minimised by reducing large tree mortality, reducing residual damage to trees that are not felled, or increasing the recruitment of priority species.

One of the most widely accepted means of reducing large tree mortality is to limit the minimum diameter at breast height (DBH) at which trees can be cut (Sist et al., 2003a). Placing such limits decreases logging intensity (volume of trees extracted $\mathrm{ha}^{-1}$ ). In addition to reducing the number of large trees felled, limiting logging intensity can also reduce residual damage to unfelled trees (Mazzei et al., 2010; Picard et al., 2012). In terms of biodiversity, recent work has shown that increases in logging intensity leads to a linear reduction in animal species richness for most vertebrates while a slight increase in bird species richness is observed at low intensities (Burivalova et al., 2014). Similarly, it is likely that species richness of trees might be enhanced at low intensities owing to an influx of shade intolerant species as suggested by the intermediate disturbance

73 hypothesis (Bongers et al., 2009; but see Fox, 2013 for a full discussion of the intermediate

74 disturbance hypothesis). 
In recent years reduced impact logging (RIL) techniques have been considered to reduce the negative environmental impacts of selective logging (Putz et al., 2008a). Though application of RIL is not uniform, it tends to involve one or more of the following activities: cutting lianas prior to logging, felling trees in predetermined directions to minimise the impact to the surrounding forest, limiting road construction, identification and mapping of trees to be cut prior to logging, and planning of roads and skid trails (Pinard and Putz 1996). Individual studies have suggested that RIL might reduce carbon emissions (Pinard and Putz, 1996), residual tree damage (Sist et al., 2003c), and result in more favourable biodiversity outcomes (Bicknell et al., 2014) when compared to conventional logging. It has also been suggested that RIL could be carried out at similar intensities to conventional logging while causing less damage to residual trees (Pinard and Putz, 1996; Putz et al., 2001; but see Sist et al., 2003). Furthermore, it has been proposed that its wide implementation could reduce global carbon emissions from selective logging by 30\% (Putz et al., 2008b). If true, these minimisations in the negative consequences of selective logging could be vital in securing long-term sustainability of timber producing tropical forests.

Despite claims made about the benefits of RIL, evidence is conflicting. Studies that investigate the effectiveness of RIL in reducing the negative impacts of conventional logging generally do so by comparing between areas logged using RIL techniques at relatively low intensities. For example, in one of the few studies comparing the effects of RIL and conventional logging on carbon stocks, any treatment effect was confounded by an approximately $50 \%$ higher logging intensity in conventionally logged plots (Pinard and Putz, 1996). Moreover, in the studies where differences in the logging intensity have been controlled for, there appears to be little difference in the impacts of RIL on the damage to residual trees (Sist et al., 2003c) and carbon stocks (Griscom et al., 2014). Taken together, these observations bring the value of RIL into question, given that a major aim of RIL is to reduce impact whilst maintaining timber yields (Keller et al., 2003).

Though RIL is widely cited as a method for limiting the negative effects of tropical selective logging there is little information regarding its general impact once logging intensities are controlled for. Though Putz et al.(2012) provided a valuable overview of the impacts of tropical selective logging on biomass and tree species richness, no attempt was made to explain differences in these impacts between sites. The recent meta-analysis by Bicknell et al. (2014) indicated that RIL reduced impacts on animal populations, but there are no equivalent syntheses of effects on trees. Given that REDD+ aims to provide economic incentives to reduce loss of carbon and biodiversity from forests (Harvey et al., 2010) and RIL has been suggested as means of attaining these reductions (Putz et al., 2008b), understanding variation in logging impacts is vital to inform management. In this study, we aim to address this knowledge gap by conducting a meta-analysis to 


\section{Methods}

determine which factors relating to logging method and intensity might explain differences in (1) residual stand damage, (2) aboveground biomass loss, and (3) tree species richness.

\section{Systematic review}

We defined selectively logged tropical forests as native forests between the latitudes of $40^{\prime} \mathrm{N}$ and 40'S subjected to selective tree removal for timber. We undertook a standard systematic review as described by Pullin and Stewart (2006) and used the terms ("biomass" OR "carbon" OR "basal area" OR "damage" OR "snag" OR "non-target" OR "tree" OR "species richness" OR biodiversity) AND (selective logg* OR felling OR timber extraction OR reduced-impact logging OR degradation) AND "tropical forest" to search Web of Knowledge, Wiley Blackwell and Science Direct databases. We also used the appendices of Clark and Covey (2012), Gibson et al. (2011), Picard et al. (2012) and Putz et al. (2012) to identify potentially relevant literature. The final literature search was undertaken on 20/06/2014. In addition, we contacted researchers working on the subject to identify any unpublished datasets. In order to be included in our analysis, studies had to:

(i) Present data on residual stand damage following logging or aboveground tree biomass and/or species richness of trees from at least one undisturbed forest and one logged forest site.

(ii) Include sites with spatially replicated measures of tree species richness or aboveground biomass of trees in both logged and unlogged sites with at least three plots present in each. This rule was relaxed for the studies of residual stand damage since very few were replicated or provided comparisons with unlogged sites.

(iii) Include logged sites that were unaffected by multiple disturbance types such as fire or drought.

(iv) Be carried out in terrestrial forests, excluding mangroves.

First, articles were excluded if titles were deemed irrelevant. Following this, abstracts were examined to filter out irrelevant articles. The remaining articles were read and retained only if they met the inclusion criteria described above. The search produced 6422 potentially relevant references and, following exclusion of irrelevant papers, we extracted data from 62. If there was evidence that relevant data had been collected but were not presented in the publications, data were requested from authors. If data were presented in tables, they were directly transferred to our database, whereas if data were presented as graphs, we used the program datathief (vIII) (Tummers, 2006) for data extraction. For details of the studies used see Table 1 and Tables S1-S3. 
In articles that measured changes in biomass or species richness, we extracted the mean, standard deviation, and sample size for sites in logged and unlogged forests. Where multiple sites were measured per study we extracted data for each site separately. In studies of forest damage, we extracted the plot level data of residual tree damage. We also recorded site latitude and longitude, continent on which studies were undertaken, method of logging used (RIL or conventional selective), the number of years since logging, the minimum size of trees measured, and volume of wood extracted $\left(\mathrm{m}^{3} \mathrm{ha}^{-1}\right)$ and/or number of trees felled ha- ${ }^{-1}$. In sites that had been logged twice, we calculated logging intensity as the sum of the volume extracted over both cycles, following Edwards et al. (2013).

Sites were defined as RIL if authors used the term to describe the logging methods used. All other sites were classified as conventional. While the definitions of RIL can vary depending on context (Putz et al., 2008a), our comparison between conventional logging and RIL represents real differences in the techniques used at sites. RIL sites tended cut lianas prior to logging more regularly than conventional sites ( $70.0 \%$ vs $10.5 \%$ of sites respectively) and the same was true for planning of roads and skidder routes (75.0\% vs 5.3\%); planned extraction of trees $(80.0 \%$ vs $21.1 \%)$; use of directional felling (65.0\% vs 5.3\%); training of staff to cause lower damage (40\% vs $0 \%$ ); supervision of staff during logging ( $25 \%$ vs $0 \%$ ) and; restriction logging on steep slopes (30.0\% vs $2.6 \%)$. On average RIL sites employed a mean $( \pm$ SE) of $4.05( \pm 0.48)$ of these techniques that aimed to reduce damage per site, while conventionally logged sites employed $0.47( \pm 0.16)$ per site. These results are summarised in Figure S1.

\section{Data preparation}

To convert the number of trees harvested $\mathrm{ha}^{-1}$ to the metric of logging intensity used in this study $\left(\mathrm{m}^{3}\right.$ wood removed ha $\left.{ }^{-1}\right)$ we produced a linear mixed model, accounting for continent level differences in the relationship between number of trees and volume of wood harvested ha ${ }^{-1}$. Following this, we used the model to predict the volume of wood harvested $\mathrm{ha}^{-1}$ in studies which only provided alternative details of the number of trees removed ha ${ }^{-1}$, following Bicknell et al. (2014) and Burivalova et al. (2014). We attempted a similar process to convert between different metrics of residual damage following Picard et al. (2012) but found that the number of trees damaged ha-1 was a poor predictor of the proportion of residual trees damaged. Therefore only studies that directly supplied information on the proportion of residual trees damaged were used.

In order to analyse the impact of logging intensity and logging method on changes in aboveground biomass and species richness, we used a weighted approach. If standard deviations were missing from studies, these were estimated by using imputation methods (Koricheva et al., 2013). To do this, we estimated the relationships between the coefficient of variation for tree 
richness or biomass and plot size using linear models since smaller sampling plots result in greater between-sample variation (Wagner et al., 2010). We then used linear models to predict the coefficient of variation for studies missing these data, which were subsequently converted to standard deviations to enable weighted analyses. While this is a relatively novel technique, it is likely to bias results less than excluding studies with incomplete information (Nakagawa and Freckleton, 2008).

\section{Statistical analysis}

To determine the effect of logging intensity and different logging methods on the proportion of residual trees damaged, an unweighted linear mixed model was used. Prior to model fitting, the response variable was logit transformed so that values were constrained between 0 and 1 (Warton and Hui, 2011). Random effects were used to identify data from the same study to avoid problems of non-independence. We tested how logging volume affected the proportion of residual trees damaged and whether logging method changed the slope of this relationship. Previous work by Picard et al. (2012) suggested that the relationship between logging damage and intensity is nonlinear, and therefore models with log terms were also tested. The marginal $\mathrm{R}^{2}$ was obtained using following the method of Nakagawa and Schielzeth (2013) implemented in the R package MuMIn (Barton, 2014). AICc was used to determine the relative likelihood of a model being the most parsimonious. All models of tree damage with a $\triangle \mathrm{AICc}<7$ were averaged to produce coefficient estimates, with models supplying more weight when they had greater support (Burnham et al., 2011).

To analyse the effects of logging on carbon pools and tree species richness, the log response ratio of differences between sites was calculated and models weighted so that more precise studies had more weight (Borenstein et al., 2009; Hedges et al., 1999, see Appendix S1). We then fitted a meta-regression model using random effects to account for between study variation that might be due to differences in research methods. In addition, in our analyses of changes in tree species richness, whether species richness estimates were rarefied or not was included as a random effect. We did this because this has been shown to cause between-study differences and was therefore considered an additional source of between-study noise (Cannon et al., 1998; Gotelli and Colwell, 2001). Random effects were also included to account for differences in the minimum DBH of trees measured and the time since logging which may have confounding effects on the analysis. Since some studies used the same unlogged site as a comparator for multiple logged sites, we ran bootstrapping routines with 10000 iterations, selecting only one pairwise comparison where the same unlogged site was used as a reference, in order to remove study-level pseudoreplication following Gibson et al., (2011). 
We tested the effects of logging method (RIL or conventional logging) and logging intensity

216 in determining changes in biomass and tree species richness. The time since a site was logged could

217 also play a role in determining logging impacts (Burivalova et al., 2014) and therefore this was also

218 included in models. After each bootstrapping iteration, models were ranked by AICc and, after

219 bootstrapping, models were ranked according to their median AICc values and the proportion of

220 times the model was considered to be the most parsimonious (Gibson et al., 2011). Parameter values

221 of the model with lowest AICc were calculated by selecting median estimates after 10000

222 bootstrapped iterations. All statistical analyses were performed in R 3.0.2 (R Development Core

223 Team, 2011) with unweighted and weighted analyses carried out using the lme4 package (Bates et

224 al., 2014) and the metafor package (Viechtbauer, 2010), respectively. All figures were drawn using

225 ggplot2 (Wickham, 2009).

\section{Results}

228 The systematic review yielded 62 studies, from which we extracted data on residual tree 229 damage from 72 sites, and 43 and 23 paired, replicated sites that measured biomass and tree species 230 richness respectively. In total these data comprised of information on residual damage from 285 231 plots, comparisons of aboveground biomass from 326 logged and 128 unlogged plots and 232 comparisons of tree species richness from 256 different logged and 161 unlogged plots. Median 233 logged-site age for those sites where biomass was measured was 4.5 years and for sites where 234 richness was measured it was 5 years. Sites were mostly located in Asia and the Americas, with 235 relatively few in Africa (Figure 1). Further details of the studies used in our meta-analysis are given 236 in Table 1 and Tables S1-S3.

The most parsimonious model for predicting the volume of wood logged ha ${ }^{-1}$ suggested a positive relationship with the number of trees extracted ha ${ }^{-1}$ an interaction between this and continent. The slope of the relationship was steeper in Asia and Africa than in the Americas (Figure $2)$ and overall the model had high explanatory power $\left(R^{2}=0.72\right)$.

\section{Residual stand damage}

The model that best explained the proportion of residual trees that were damaged included an interaction between the logarithm of logging intensity and the logging method $\left(\mathrm{R}^{2}=0.25\right)$. Only one other model had a $\triangle \mathrm{AICc}<7$ (Table 2). Model-averaged predictions suggested that residual damage increased as a function of the logarithm of the logging intensity (Slope $=0.54 \pm 0.19$, $\mathrm{P}=0.005$, Figure 2, Table S3). This model also suggested that RIL tended to cause less residual damage than conventional logging at the range of intensities studied (coefficient $=-1.00 \pm 0.37$, $\mathrm{P}=0.007$, Figure 2 , Table S4). However, the $95 \%$ confidence intervals for predictions were wide 
indicating large variation in damage to residual tree stems for both methods.

\section{Impacts of logging intensity and method on biomass and species richness}

Logging intensity was negatively correlated with the response ratio for aboveground

biomass following logging (slope $=-0.0042 \pm$ SE 0.0008, $\mathrm{P}<0.001$, Figure 4a, Table S5). This model had good explanatory power (pseudo- $\mathrm{R}^{2}=0.43$ ) and was ranked most parsimonious in all bootstrap iterations (Table 3). Logging intensity was considered the most important variable for predicting post-logging change in biomass as it was present in all models with a $\triangle \mathrm{AICc} \leq 7$ (Table 3 ). However, it is also clear that there is no model that performs substantially better than all of the others since numerous models had a $\triangle \mathrm{AICc} \leq 7$. In addition the relatively low intensities at which RIL sites tended to be logged compared to conventional sites reduced the power of our analyses to detect differences in impacts between the two methods (Figure 4a).

The model that explained variation in tree species richness response ratio most effectively indicated a negative relationship with intensity of logging (slope $=-0.001 \pm \mathrm{SE} 0.0002, \mathrm{P}<0.001$ ), with a positive intercept (Intercept $=0.06 \pm 0.01, \mathrm{P}<0.001$, Figure $4 \mathrm{~b}$, Table 4 , Table S6). Only one other model had a $\triangle \mathrm{AICc}<7$, and the most parsimonious model had a pseudo- $\mathrm{R}^{2}$ of 0.34 . As with aboveground biomass, the relatively low logging intensities used in RIL hindered comparison of the effects of the different methods while accounting for intensity (Figure 4b).

\section{Discussion}

This study draws on a larger body of evidence than the recent meta-analysis of Putz et al. (2012) on the impacts of selective tropical logging, making it the most precise meta-analysis of the impacts of tropical selective logging on carbon and tree biodiversity to date. In addition, our analyses of the impacts of logging on biomass and species richness accounted for (i) differences in study precision, (ii) study-level pseudoreplication, and (iii) explored the reasons for variation in impacts amongst sites. While the meta-analysis of Putz et al. (2012) was a valuable contribution to the logging literature it did not address any of these issues and as a result the results of our study differ substantially from this previous meta-analysis.

Our results indicate that the impacts of selective logging in tropical forests on residual stand damage, biomass loss and species richness change are largely explained by differences in logging intensity. Residual tree damage also appears to be reduced under RIL when compared to conventional logging. However, the effect of RIL on biomass loss was difficult to assess owing to the confounding effects of differences in logging intensity, a problem that is not widely acknowledged in the literature on tropical forest logging. Below we discuss implications of our results and potential solutions to this problem. 


\section{Impacts of logging on stand damage and biomass}

Our meta-analysis indicates that logging intensity is the primary driver of differences in non-target tree damage in selectively logged tropical forests, as noted in previous studies (Johns, 1992; Picard et al., 2012; Sist et al., 1998). However, our results from a wide range of sites also support the hypothesis that RIL causes lower damage to residual trees than conventional logging the first time that such as result has been noted across a large number of different sites. Given that residual damage to trees can account for $20-30 \%$ of biomass losses from selective logging as a result of increased mortality from windthrow, disease or fire (Johns, 1992; Mazzei et al., 2010; Panfil and Gullison, 1998), our result indicates that RIL may help to reduce carbon losses at the stand scale. In addition, our results suggest that in order to keep residual stand damage below the 25-30\% limit that is considered to be sustainable (Huth and Ditzer, 2001; Sist et al., 2003a, 2003b), RIL should be carried out at intensities below $60 \mathrm{~m}^{3} \mathrm{ha}^{-1}$ while conventional logging must be limited to intensities below $40 \mathrm{~m}^{3} \mathrm{ha}^{-1}$ (Figure 3).

A large amount of between-study variation was observed in the impacts of logging intensity and methods on stem damage, which suggests that variables we failed to consider may be important, such as the density of log extraction routes or the steepness of slopes where logging was undertaken (Putz et al., 2000). Equally, this variation may be a result of the amongst study differences in methods and metrics used to assess stem damage, as previously noted by Putz et al. (2008a). Our results support Putz et al.'s (2008a) assertion that standardised metrics of logging damage are needed to enable synthesis.

Our analyses of the effects of logging on aboveground biomass emphasize that accounting for harvesting intensity is vital. The volume of wood removed ha ${ }^{-1}$ was by far the best predictor of changes in biomass in response to timber harvest. While this point may appear obvious, many studies fail to interpret the effects of logging in the context of the intensity used. For example, the

311 forests," failing to statistically account for differences in logging intensity. However, results from 312 our study show that this finding of Putz et al., (2012)is only true when forests are logged at an 313 intensity of approximately $50 \mathrm{~m}^{3} \mathrm{ha}^{-1}$ and that there is considerable variation in logging impacts 314 which are driven by logging intensity Thus, reporting the mean impact of logging on biomass as 315 Putz et al., (2012) did is relatively uninformative.

We found little support for the hypothesis that RIL and conventional selective logging

317 differed in their effect on post-logging biomass once logging intensity is accounted for. As such it is 318 impossible to say, from the studies used here, whether RIL causes lower carbon emissions when 319 compared to conventional logging. In part this results from a lack of data from studies of RIL, and 
the relatively low logging intensities at which RIL is carried out when compared to conventional selective logging (Figure 5). Keller et al.(2003) argued that RIL is not synonymous with low-yield logging. However, the data used in our study and recommendations by Sist et al. (2003a, 2003c) suggest that part of the prescriptions for RIL may be a reduction in logging intensity. In order to compare the impacts of RIL and conventional logging further clarification is needed on whether RIL is inherently a low intensity practice. Ultimately, timber yields are extremely important for managers of logging concessions and if RIL will always reduce short-term yield this must be explicit. Given the important of yields, even if RIL is essentially a low intensity practice consideration of impacts must account for differences in intensity. Unless studies of RIL are carried out at a similar range of intensities to conventional selective logging its potential benefits, aside from those resulting from lower logging intensities, will remain difficult to assess.

While our study found relatively little evidence for the benefits of RIL for aboveground carbon pools we acknowledge that there is evidence from studies that did not fit our selection criteria that merits consideration. For example, Pereira et al., (2002) found that the size of logging gaps, and thus loss of carbon, was reduced in forests logged using RIL compared to forests logged using conventional methods at similar intensities. In a study that also controlled for logging intensity, West et al. (2014) showed that in a single 24.5 ha plot logged using RIL biomass was reduced by approximately $20 \%$ compared to $25 \%$ for a plot logged using conventional methods. However, in contrast a recent field study suggested that once logging intensity is controlled for there is little difference between the impacts of RIL and conventional methods on carbon storage (Griscom et al., 2014). There is therefore currently relatively little agreement between field-based studies on the carbon benefits of RIL.

Modelling studies have suggested that over 40-60 years the carbon benefits of RIL may be magnified owing to a reduction in residual damage (Pinard and Cropper, 2000; Putz et al., 2008b). Given that growth of non-target trees is important for carbon sequestration in forests recovering from tropical selective logging (Gourlet-Fleury et al., 2013b), the reduction in residual damage observed in this and other studies points to the potential for RIL to have longer-term carbon benefits that our meta-analysis may not have accounted for. These benefits have been hinted at previously (e.g. Lincoln, 2008; West et al., 2014) but there are currently too few studies to discern whether forests logged using RIL do indeed recover biomass more quickly than conventionally logged forests.

\section{Impacts of logging on species richness}

As for aboveground biomass, logging intensity best explained differences in tree species richness caused by logging. However, compared to aboveground biomass, the slope of this 
relationship was much less steep, with an apparent initial increase in species richness at low intensities. In addition the wide confidence intervals around predictions (Figure $4 \mathrm{~b}$ ) indicate the widespread variation in impacts. The most plausible explanation for a post-logging increase in richness is an influx of generalist species from surrounding non-forest areas (Carreño-Rocabado et al., 2012) leading to an initial post-harvest increase, in-line with previous observations supporting

the general pattern of the intermediate disturbance hypothesis (Bongers et al., 2009; Connell, 1978). Similar relationships have recently been observed between logging intensity and bird species richness, while other vertebrates showed a decline even at low intensities (Burivalova et al., 2014). Our results suggest that tree species richness may be relatively insensitive to subtle changes in forest cover, as has been noted previously (Cannon et al., 1998). However, changes in species richness provide no information about the identity and function of individual species. Community composition is likely to be impacted by selective logging, with forest-dependent species sensitive to disturbance becoming less abundant or locally extinct (Sheil et al., 1999) and generalist species increasing in abundance (Baraloto et al., 2012; Gourlet-Fleury et al., 2013). However, analysis of logging impacts on community composition is hindered by the fact that most studies of logging are spatially pseudo-replicated, leading to biased estimates of change (Ramage et al., 2013). Despite this pseudo-replication investigation of the functional traits that determine species' presence and abundance in logged forests could prove a fruitful line of research, as has recently been done with bird species (Newbold et al., 2013).

\section{Improving assessments of logging intensity and damage}

Our analyses support conclusions by others (Bicknell et al., 2014; Burivalova et al., 2014) that consideration of logging intensity is vital to understand the impact of logging on biodiversity and aboveground biomass. While this is a seemingly obvious point, many studies interpret logging impacts without reference to logging intensity. One reason for this is that it can be difficult to obtain statistics on the volume of wood removed from an area, and when such data are available they are often only available as a mean volume removed $\mathrm{ha}^{-1}$ for the entire study area. For individual studies, identification of the importance of logging intensity is extremely difficult. To solve this, the use of metrics of logging intensity such as basal area logged ha ${ }^{-1}$ may prove fruitful (Mazzei et al., 2010). This has the advantage of allowing an estimate of logging intensity at the plot scale, allowing for more nuanced analyses of logging impacts than is currently possible for most studies. Connected to this point, though we are confident that the methods used in RIL and conventional sites differed, detailed descriptions of the methods used for logging were rare. Where possible studies should report in detail on the logging methods used to allow for easier comparison between studies. A wide variety of different measures are used to assess residual logging damage in 
390

391

392

393

394

395

396

397

398

399

400

401

402

403

404

405

406

407

408

409

410

411

412

413

414

415

416

417

418

419

420

421

422

423

424

selectively logged forest stands (Picard et al. 2012), fostered by different objectives and hypotheses.

We attempted to convert between different measures to maximise the value of available data, but found that this was not possible due to the poor descriptive value of models. Future syntheses would be aided by standardisation of metrics. As Putz et al. (2008a) and Picard et al., (2012) previously recommended, we support the use of standardised metrics that assess tree damage at the level of individual trees. We also suggest that future studies should report the proportion of basal area that is damaged to provide additional information of logging impacts on forest biomass. Furthermore, stratification of logging damage by tree size class would allow an assessment of its potential demographic effects and would therefore aid our understanding of the recovery of logged forests.

\section{Reducing the negative effects of logging}

The results of our study and those of Burivalova et al. (2014) suggest that logging intensity drives carbon and species loss while Becknell et al. (2014) suggest that RIL is less damaging for animal populations. As such, current evidence suggests that RIL at relatively low intensities is likely to be the best way to reduce carbon and biodiversity loss in tropical logged forests. However, given the massive area of tropical forest already designated for logging (Asner et al., 2009), reductions in local intensity, and therefore timber yield, may encourage expansion into previously unlogged areas. This mirrors the situation in agricultural landscapes where the biodiversity benefits of highyield farming in small areas as opposed to low-yield, extensive farming is debated (Phalan et al., 2011; Rey Benayas et al., 2012). The land-sparing/sharing framework is becoming more prevalent in the logging literature (Griscom and Goodman, 2015), and the only empirical study of this to date suggests that high intensity logging over a smaller area ('land sparing') has better outcomes for tropical forest species than low-intensity extensive timber extraction ('land sharing') in Borneo (Edwards et al., 2014). We hope that the recognition of the importance of timber yields in this context will encourage a more realistic debate about the value of different logging methods and how to balance yields and environmental priorities.

Although reductions in logging intensity may reduce impact, the high demand for timber requires solutions that do not drastically reduce current yields but reduce impacts on forest ecosystems. Methods such as thinning to remove non-timber tree species appear to aid recovery of floral community composition (Ouédraogo et al., 2011), carbon (Gourlet-Fleury et al., 2013b) and timber stocks (Peña-Claros et al., 2008a), and if used in conjunction with other techniques may improve the sustainability of selective logging. When silvicultural treatments are implemented their impacts on different species will need careful consideration so that the growth and recruitment of priority species can be maximised (Peña-Claros et al., 2008b). RIL, along with other measures such as silvicultural treatments, increasing the length of logging cycles and reductions in logging 
intensity, may help to improve the sustainability of tropical timber production (Huth and Ditzer, 2001; Pinard and Cropper, 2000; Sist et al., 2003a). However, further evidence is required to verify the benefits of RIL for aboveground carbon storage and tree biodiversity. One potential solution to this lack of evidence is the use of existing data from collaborative networks such as The Tropical Managed Forests Observatory (Sist et al., 2015) while accounting for between-plot variation in logging intensity. Such analyses would contribute towards more sustainable tropical logging practice by providing a more robust evidence base than is currently available.

\section{Acknowledgements}

PM would like to thank NERC for providing PhD funding. MP and MSK thank Sime Darby for funding of the SAFE project. This paper is a contribution to Imperial College's Grand Challenges in Ecosystems and the Environment initiative. Thanks are due to Louise Barwell for statistical advice and to anonymous reviewers of a previous version of this manuscript.

\section{References}

Asner, G.P., Rudel, T.K., Aide, T.M., Defries, R., Emerson, R., Evaluaci, U., 2009. A Contemporary Assessment of Change in Humid Tropical Forests. Conserv. Biol. 23, 13861395. doi:10.1111/j.1523-1739.2009.01333.x

Baraloto, C., Hérault, B., Paine, C.E.T., Massot, H., Blanc, L., Bonal, D., Molino, J.-F., Nicolini, E. a., Sabatier, D., 2012. Contrasting taxonomic and functional responses of a tropical tree community to selective logging. J. Appl. Ecol. 49, 861-870. doi:10.1111/j.13652664.2012.02164.x

Barton, K., 2014. MuMIn: Multi-model inference.

Bates, D., Maechler, M., Bolker, B., Walker, S., 2014. lme4: Linear mixed-effects models using Eigen and S4. ArXiv.

Berry, N.J., Phillips, O.L., Lewis, S.L., Hill, J.K., Edwards, D.P., Tawatao, N.B., Ahmad, N., Magintan, D., Khen, C. V., Maryati, M., Ong, R.C., Hamer, K.C., 2010. The high value of logged tropical forests: lessons from northern Borneo. Biodivers. Conserv. 19, 985-997. doi:10.1007/s10531-010-9779-z

Berry, N.J., Phillips, O.L., Ong, R.C., Hamer, K.C., 2008. Impacts of selective logging on tree diversity across a rainforest landscape: the importance of spatial scale. Landsc. Ecol. 23, 915929.

Bicknell, J.E., Struebig, M.J., Davies, Z.G., 2015. Reconciling timber extraction with biodiversity conservation in tropical forests using reduced-impact logging. J. Appl. Ecol. n/a-n/a. doi:10.1111/1365-2664.12391 
Bicknell, J.E., Struebig, M.J., Edwards, D.P., Davies, Z.G., 2014. Improved timber harvest techniques maintain biodiversity in tropical forests. Curr. Biol. 24, 5-6. doi:10.1016/j.cub.2014.10.067

Blaser, J., Sarre, A., Poore, D., Johnson, S., 2011. Status of tropical forest management 2011. ITTO Technical Series No 38. International Tropical Timber Organization, Yokohama, Japan.

Bongers, F., Poorter, L., Hawthorne, W.D., Sheil, D., 2009. The intermediate disturbance hypothesis applies to tropical forests, but disturbance contributes little to tree diversity. Ecol. Lett. 12, 798-805. doi:10.1111/j.1461-0248.2009.01329.x

Borenstein, M., Hedges, L. V, Higgins, J.P.T., Rothstein, H.R., 2009. Introduction to MetaAnalysis. Wiley Online Library.

Bryan, J., Shearman, P., Ash, J., 2010. Impact of logging on aboveground biomass stocks in lowland rain forest, Papua New Guinea. Ecol. Appl. 20, 2096-2103.

Burghouts, T.B. a., Campbell, E.J.F., Kolderman, P.J., 1994. Effects of tree species heterogeneity on leaf fall in primary and logged dipterocarp forest in the Ulu Segama Forest Reserve, Sabah, Malaysia. J. Trop. Ecol. doi:10.1017/S0266467400007677

Burivalova, Z., Sekercioğlu, C.H., Koh, L.P.P.P., Şekercioğlu, Ç.H., Koh, L.P.P.P., Şekercioğlu, Ç.H.H., Koh, L.P.P.P., 2014. Thresholds of Logging Intensity to Maintain Tropical Forest Biodiversity. Curr. Biol. 24, 1893-1898. doi:10.1016/j.cub.2014.06.065

Burnham, K.P., Anderson, D.R., Huyvaert, K.P., 2011. AIC model selection and multimodel inference in behavioral ecology: some background, observations, and comparisons. Behav. Ecol. Sociobiol. 65, 23-35.

Cannon, C., Peart, D., Leighton, M., 1998. Tree species diversity in commercially logged bornean rainforest. Science 281, 1366-8.

Cannon, C.H., Peart, D.R., Leighton, M., 1998. Tree species diversity in commercially logged Bornean rainforest. Science (80-. ). 281, 1366-1368.

Carreño-Rocabado, G., Peña-Claros, M., Bongers, F., Alarcón, A., Licona, J.-C., Poorter, L., 2012. Effects of disturbance intensity on species and functional diversity in a tropical forest. J. Ecol. 100, 1453-1463. doi:10.1111/j.1365-2745.2012.02015.x

Connell, J.H., 1978. Diversity in tropical rain forests and coral reefs. Science (80-. ). 199, 13021310.

D’Oliveira, M.V.N., Reutebuch, S.E., McGaughey, R.J., Andersen, H.-E., 2012. Estimating forest biomass and identifying low-intensity logging areas using airborne scanning lidar in Antimary State Forest, Acre State, Western Brazilian Amazon. Remote Sens. Environ. 124, 479-491. doi:10.1016/j.rse.2012.05.014

Edwards, D.P., Gilroy, J.J., Woodcock, P., Edwards, F.A., Larsen, T.H., Andrews, D.J.R., Derhé, M.A., Docherty, T.D.S., Hsu, W.W., Mitchell, S.L., Ota, T., Williams, L.J., Laurance, W.F., Hamer, K.C., Wilcove, D.S., 2014. Land-sharing versus land-sparing logging: Reconciling timber extraction with biodiversity conservation. Glob. Chang. Biol. 20, 183-191. doi:10.1111/gcb.12353 
Foody, G.M., Cutler, M.E.J., 2003. Tree biodiversity in protected and logged Bornean tropical rain forests and its measurement by satellite remote sensing. J. Biogeogr. 30, 1053-1066. doi:10.1046/j.1365-2699.2003.00887.x

Fox, J.W., 2013. The intermediate disturbance hypothesis should be abandoned. Trends Ecol. Evol. 28, 86-92. doi:10.1016/j.tree.2012.08.014

Gatti, R.C., Castaldi, S., Lindsell, J.A., Coomes, D.A., Marchetti, M., Maesano, M., Di Paola, A., Paparella, F., Valentini, R., 2014. The impact of selective logging and clearcutting on forest structure, tree diversity and above-ground biomass of African tropical forests. Ecol. Res. 30, 119-132. doi:10.1007/s11284-014-1217-3

Gerwing, J.J., 2002. Degradation of forests through logging and fire in the eastern Brazilian Amazon. For. Ecol. Manage. 157, 131-141. doi:10.1016/S0378-1127(00)00644-7

Gibson, L., Lee, T.M., Koh, L.P., Brook, B.W., Gardner, T. a, Barlow, J., Peres, C. a, Bradshaw, C.J. a, Laurance, W.F., Lovejoy, T.E., Sodhi, N.S., 2011. Primary forests are irreplaceable for sustaining tropical biodiversity. Nature 478, 378-81. doi:10.1038/nature10425

Gotelli, N.J., Colwell, R.K., 2001. Quantifying biodiversity: procedures and pitfalls in the measurement and comparison of species richness. Ecol. Lett. 4, 379-391.

Gourlet-Fleury, S., Beina, D., Fayolle, A., Ouédraogo, D.Y., Mortier, F., Bénédet, F., ClossetKopp, D., Decocq, G., 2013a. Silvicultural disturbance has little impact on tree species diversity in a Central African moist forest. For. Ecol. Manage. 304, 322-332. doi:10.1016/j.foreco.2013.05.021

Gourlet-Fleury, S., Mortier, F., Fayolle, A., Baya, F., Ouédraogo, D., Bénédet, F., Picard, N., Ouedraogo, D., Benedet, F., Picard, N., Ouédraogo, D., Bénédet, F., Picard, N., 2013b. Tropical forest recovery from logging: a 24 year silvicultural experiment from Central Africa. Philos. Trans. R. Soc. Lond. B. Biol. Sci. 368, 1-10. doi:10.1098/rstb.2012.0302

Griscom, B., Ellis, P., Putz, F.E., 2014. Carbon emissions performance of commercial logging in East Kalimantan, Indonesia. Glob. Chang. Biol. 20, 923-37. doi:10.1111/gcb.12386

Griscom, B.W., Goodman, R.C., 2015. Reframing the sharing vs sparing debate for tropical forestry landscapes 27, 145-147.

Harvey, C.A., Dickson, B., Kormos, C., 2010. Opportunities for achieving biodiversity conservation through REDD. Conserv. Lett. 3, 53-61.

Hedges, L.V. V, Gurevitch, J., Curtis, P.S.S., 1999. The meta-analysis of response ratios in experimental ecology. Ecology 80, 1150-1156.

Huth, A., Ditzer, T., 2001. Long-term impacts of logging in a tropical rain forest - a simulation study. For. Ecol. Manage. 142, 33-51.

Imai, N., Seino, T., Aiba, S., Takyu, M., Titin, J., Kitayama, K., 2012. Effects of selective logging on tree species diversity and composition of Bornean tropical rain forests at different spatial scales. Plant Ecol. 213, 1413-1424. doi:10.1007/s11258-012-0100-y 
Johns, A.D., 1992. Species Conservation in managed tropical forests, in: Whitmore, T.C., Sayer, J.A. (Eds.), Tropical Deforestation and Species Extinction. Springer, London, pp. 15-50.

Keller, M., Asner, G.P., Silva, J.N.M., Palace, M., 2003. Sustainability of Selective Logging of Upland Forests in the Brazilian Amazon: Carbon Budgets and Remote Sensing as Tools for Evaluation of Logging Effects. Work. For. Trop. Conserv. through Sustain. Manag. 39.

Koricheva, J., Gurevitch, J., Mengeresen, K., 2013. Handbook of meta-analysis in ecology and evolution. Princeton University Press.

Lincoln, P., 2008. Stalled gaps or rapid recovery - The influence of damage on post-logging Forest dynamics and carbon balance. University of Aberdeen.

Mazzei, L., Sist, P., Ruschel, A., Putz, F.E., Marco, P., Pena, W., Ferreira, J.E.R., 2010. Aboveground biomass dynamics after reduced-impact logging in the Eastern Amazon. For. Ecol. Manage. 259, 367-373. doi:10.1016/j.foreco.2009.10.031

Medjibe, V.P., Putz, F.E., Romero, C., 2013. Certified and uncertified logging concessions compared in Gabon: changes in stand structure, tree species, and biomass. Environ. Manage. 51, 524-40. doi:10.1007/s00267-012-0006-4

Medjibe, V.P., Putz, F.E., Starkey, M.P., Ndouna, A.A., Memiaghe, H.R., 2011. Impacts of selective logging on above-ground forest biomass in the Monts de Cristal in Gabon. For. Ecol. Manage. 262, 1799-1806.

Nakagawa, S., Freckleton, R.P., 2008. Missing inaction: the dangers of ignoring missing data. Trends Ecol. Evol. doi:10.1016/j.tree.2008.06.014

Nakagawa, S., Schielzeth, H., 2013. A general and simple method for obtaining R 2 from generalized linear mixed-effects models. Methods Ecol. Evol. 4, 133-142. doi:10.1111/j.2041210x.2012.00261.x

Nepstad, D.C., Verissimo, A., Alencar, A., Nobre, C., Lima, E., Lefebvre, P., Schlesinger, P., Potter, C., Moutinho, P., Mendoza, E., 1999. Large-scale impoverishment of Amazonian forests by logging and fire. Nature 398, 505-508.

Newbold, T., Scharlemann, J.P.W., Butchart, S.H.M., Şekercioğlu, Ç.H., Alkemade, R., Booth, H., Purves, D.W., 2013. Ecological traits affect the response of tropical forest bird species to landuse intensity. Proc. R. Soc. B Biol. Sci. 280.

Ouédraogo, D.-Y., Beina, D., Picard, N., Mortier, F., Baya, F., Gourlet-Fleury, S., 2011. Thinning after selective logging facilitates floristic composition recovery in a tropical rain forest of Central Africa. For. Ecol. Manage. doi:10.1016/j.foreco.2011.08.009

Panfil, S.N., Gullison, R.E., 1998. Short term impacts of experimental timber harvest intensity on forest structure and composition in the Chimanes Forest , Bolivia 235-243.

Peña-Claros, M., Fredericksen, T.S., Alarcón, a., Blate, G.M., Choque, U., Leaño, C., Licona, J.C., Mostacedo, B., Pariona, W., Villegas, Z., Putz, F.E., 2008a. Beyond reduced-impact logging: Silvicultural treatments to increase growth rates of tropical trees. For. Ecol. Manage. 256, 1458-1467. doi:10.1016/j.foreco.2007.11.013 
Peña-Claros, M., Peters, E.M., Justiniano, M.J., Bongers, F., Blate, G.M., Fredericksen, T.S., Putz, F.E., 2008b. Regeneration of commercial tree species following silvicultural treatments in a moist tropical forest. For. Ecol. Manage. 255, 1283-1293. doi:10.1016/j.foreco.2007.10.033

Pereira, R., Zweede, J., Asner, G.P., Keller, M., 2002. Forest canopy damage and recovery in reduced-impact and conventional selective logging in eastern Para, Brazil. For. Ecol. Manage. 168, 77-89. doi:10.1016/S0378-1127(01)00732-0

Pfeifer, M., Lefebvre, V., Cusack, J., Khoo, M., Chey, V.K., 2015. Deadwood biomass: an underestimated fraction of aboveground carbon stocks in degraded tropical forests? Environ. Res. Lett. 10.

Phalan, B., Onial, M., Balmford, A., Green, R.E., 2011. Reconciling food production and biodiversity conservation: land sharing and land sparing compared. Science (80-. ). 333, 12891291. doi:10.1126/science. 1208742

Picard, N., Gourlet-Fleury, S., Forni, É., 2012. Estimating damage from selective logging and implications for tropical forest management. Can. J. For. Res. doi:10.1139/x2012-018

Pinard, M., Putz, F.E., 1996. Retaining forest biomass by reducting logging damage. Biotropica 28, 278-295.

Pinard, M.A., Cropper, W.P., 2000. Simulated effects of logging on carbon storage in dipterocarp forest. J. Appl. Ecol. 37, 267-283.

Pullin, A.S., Stewart, G.B., 2006. Guidelines for systematic review in conservation and environmental management. Conserv. Biol. 20, 1647-1656. doi:10.1111/j.15231739.2006.00485.x

Putz, F.E., Blate, G.M., Redford, K.H., Fimbel, R., Robinson, J., 2001. Tropical forest management and conservation of biodiversity: an overview. Conserv. Biol. 15, 7-20.

Putz, F.E., Dykstra, D.P., Heinrich, R., 2000. Why Poor Logging Practices Persist in the Tropics. Conserv. Biol. 14, 951-956. doi:10.1046/j.1523-1739.2000.99137.x

Putz, F.E., Sist, P., Fredericksen, T., Dykstra, D., 2008a. Reduced-impact logging: Challenges and opportunities. For. Ecol. Manage. 256, 1427-1433. doi:10.1016/j.foreco.2008.03.036

Putz, F.E., Zuidema, P. a., Synnott, T., Peña-Claros, M., Pinard, M. a., Sheil, D., Vanclay, J.K., Sist, P., Gourlet-Fleury, S., Griscom, B., Palmer, J., Zagt, R., 2012. Sustaining conservation values in selectively logged tropical forests: the attained and the attainable. Conserv. Lett. 5, 296-303. doi:10.1111/j.1755-263X.2012.00242.X

Putz, F.E., Zuidema, P.A., Pinard, M.A., Boot, R.G.A., Sayer, J.A., Sheil, D., Sist, P., Elias, Vanclay, J.K., 2008b. Improved tropical forest management for carbon retention. PLoS Biol. 6, 1368-1369. doi:10.1371/journal.pbio.0060166

R Development Core Team, 2011. R: A Language and Environment for Statistical Computing. R Foundation for Statistical Computing, Vienna, Austria.

Ramage, B.S., Sheil, D., Salim, H.M.W., Fletcher, C., Mustafa, N.-Z.A.N.A., Luruthusamay, J.C., Harrison, R.D., Butod, E., Dzulkiply, A.D., Kassim, A.R., Potts, M.D., 2013. 
Pseudoreplication in Tropical Forests and the Resulting Effects on Biodiversity Conservation. Conserv. Biol. 27, 364-372. doi:10.1111/cobi.12004

Rey Benayas, J.M., Bullock, J.M., Rey Benayas, J.M., Bullock, J.M., 2012. Restoration of biodiversity and ecosystem services on agricultural land. Ecosystems 15, 883-899.

Rockwell, C.A., Kainer, K.A., Vinicio, M., Staudhammer, C.L., Baraloto, C., 2014. Forest Ecology and Management Logging in bamboo-dominated forests in southwestern Amazonia : Caveats and opportunities for smallholder forest management. For. Ecol. Manage. 315, 202-210. doi:10.1016/j.foreco.2013.12.022

Saner, P., Loh, Y.Y., Ong, R.C., Hector, A., 2012. Carbon stocks and fluxes in tropical lowland dipterocarp rainforests in Sabah, Malaysian Borneo. PLoS One 7, e29642. doi:10.1371/journal.pone.0029642

Shearman, P., Bryan, J., Laurance, W.F., 2012. Are we approaching "peak timber" in the tropics? Biol. Conserv. 151, 17-21. doi:http://dx.doi.org/10.1016/j.biocon.2011.10.036

Sheil, D., Sayer, J.A., O’Brien, T., 1999. Tree species diversity in logged rainforests. Science (80-. ). 284, 1587.

Sist, P., Fimbel, R., Sheil, D., Nasi, R., Chevallier, M.-H., 2003a. Towards sustainable management of mixed dipterocarp forests of South-east Asia: moving beyond minimum diameter cutting limits. Environ. Conserv. 30, 364-374. doi:10.1017/S0376892903000389

Sist, P., Mazzei, L., Blanc, L., Rutishauser, E., 2014. Large trees as key elements of carbon storage and dynamics after selective logging in the Eastern Amazon. For. Ecol. Manage. 318, 103109. doi:10.1016/j.foreco.2014.01.005

Sist, P., Nolan, T., Bertault, J.-G., Dykstra, D., 1998. Harvesting intensity versus sustainability in Indonesia. For. Ecol. Manage. 108, 251-260. doi:http://dx.doi.org/10.1016/S03781127(98)00228-X

Sist, P., Picard, N., Gourlet-Fleury, S., 2003b. Sustainable cutting cycle and yields in a lowland mixed dipterocarp forest of Borneo. Ann. For. Sci. 60, 803-814.

Sist, P., Rutishauser, E., Peña-Claros, M., Shenkin, A., Hérault, B., Blanc, L., Baraloto, C., Baya, F., Benedet, F., da Silva, K.E., Descroix, L., Ferreira, J.N., Gourlet-Fleury, S., Guedes, M.C., Bin Harun, I., Jalonen, R., Kanashiro, M., Krisnawati, H., Kshatriya, M., Lincoln, P., Mazzei, L., Medjibé, V., Nasi, R., d'Oliveira, M.V.N., de Oliveira, L.C., Picard, N., Pietsch, S., Pinard, M., Priyadi, H., Putz, F.E., Rodney, K., Rossi, V., Roopsind, A., Ruschel, A.R., Shari, N.H.Z., Rodrigues de Souza, C., Susanty, F.H., Sotta, E.D., Toledo, M., Vidal, E., West, T.A.P., Wortel, V., Yamada, T., 2015. The Tropical managed Forests Observatory: a research network addressing the future of tropical logged forests. Appl. Veg. Sci. 18, 171-174. doi:10.1111/avsc. 12125

Sist, P., Sheil, D., Kartawinata, K., Priyadi, H., 2003c. Reduced-impact logging in Indonesian Borneo: some results confirming the need for new silvicultural prescriptions. For. Ecol. Manage. 179, 415-427. doi:10.1016/S0378-1127(02)00533-9 
Tangki, H., Chappell, N. a., 2008. Biomass variation across selectively logged forest within a 225$\mathrm{km} 2$ region of Borneo and its prediction by Landsat TM. For. Ecol. Manage. 256, 1960-1970. doi:10.1016/j.foreco.2008.07.018

Tummers, B., 2006. DataThief III. <http://datathief.org/>.

Viechtbauer, W., 2010. Conducting Meta-Analyses in R with the metafor Package. J. Stat. Softw. $36,1-48$.

Villela, D.M., Nascimento, M.T., Aragao, L.E.O.C., da Gama, D.M., 2006. Effect of selective logging on forest structure and nutrient cycling in a seasonally dry Brazilian Atlantic forest. J. Biogeogr. 33, 506-516. doi:10.1111/j.1365-2699.2005.01453.x

Wagner, F., Rutishauser, E., Blanc, L., Herault, B., 2010. Effects of Plot Size and Census Interval on Descriptors of Forest Structure and Dynamics. Biotropica 42, 664-671. doi:10.1111/j.17447429.2010.00644.x

Warton, D.I., Hui, F.K.C., 2011. The arcsine is asinine: The analysis of proportions in ecology. Ecology 92, 3-10. doi:10.1890/10-0340.1

Webb, E.L., Peralta, R., 1998. Tree community diversity of lowland swamp forest in Northeast Costa Rica, and changes associated with controlled selective logging. Biodivers. Conserv. 7, 565-583.

West, T.A.P.P., Vidal, E., Putz, F.E., 2014. Forest biomass recovery after conventional and reduced-impact logging in Amazonian Brazil. For. Ecol. Manage. 314, 59-63. doi:10.1016/j.foreco.2013.11.022

Wickham, H., 2009. ggplot2: elegant graphics for data analysis. Springer, New York. 


\section{Figures}

674
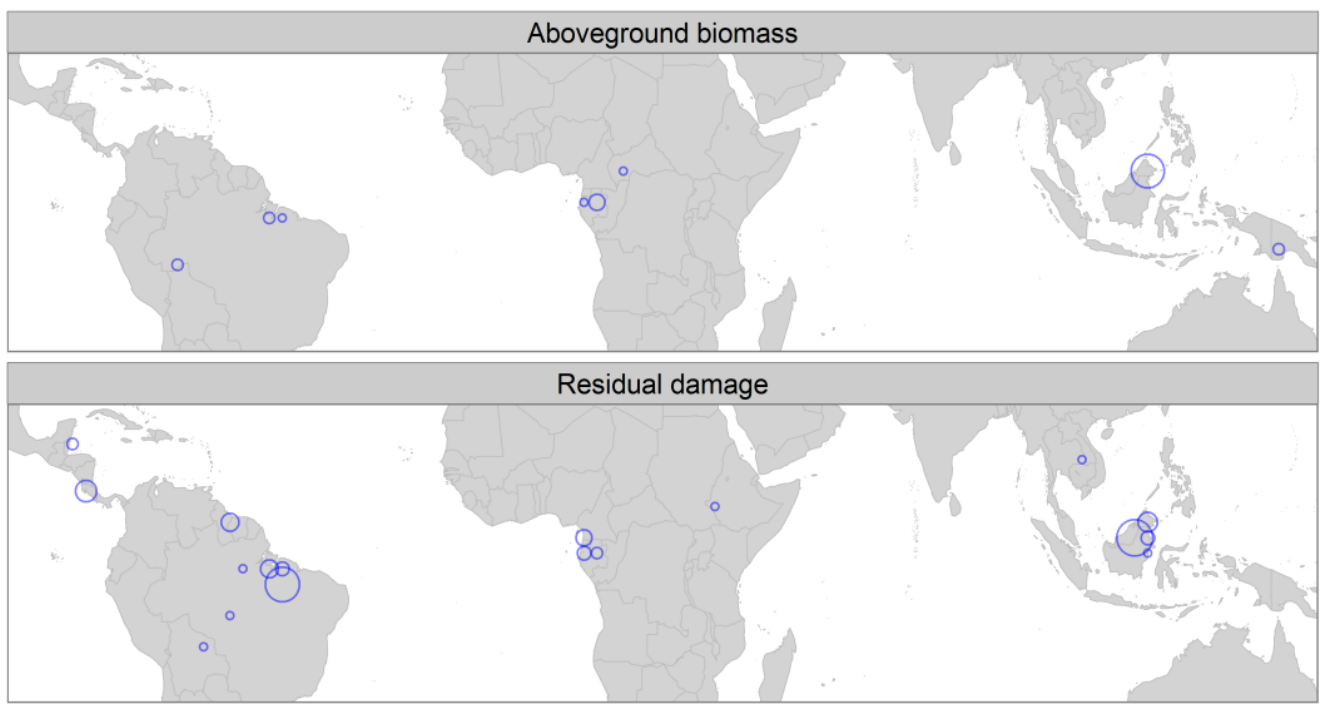

No. of sites
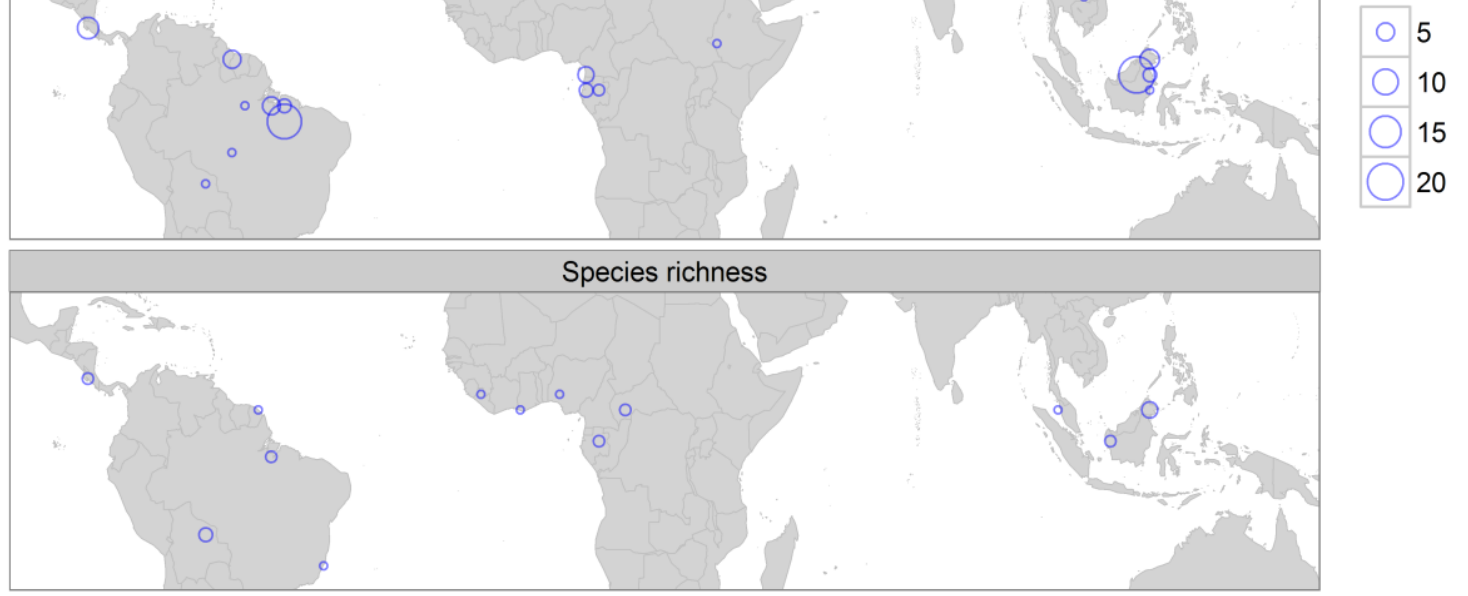

675

676 Figure 1 - Geographic location of studies used in our meta-analyses of residual damage,

677 aboveground biomass and species richness responses to selective logging 


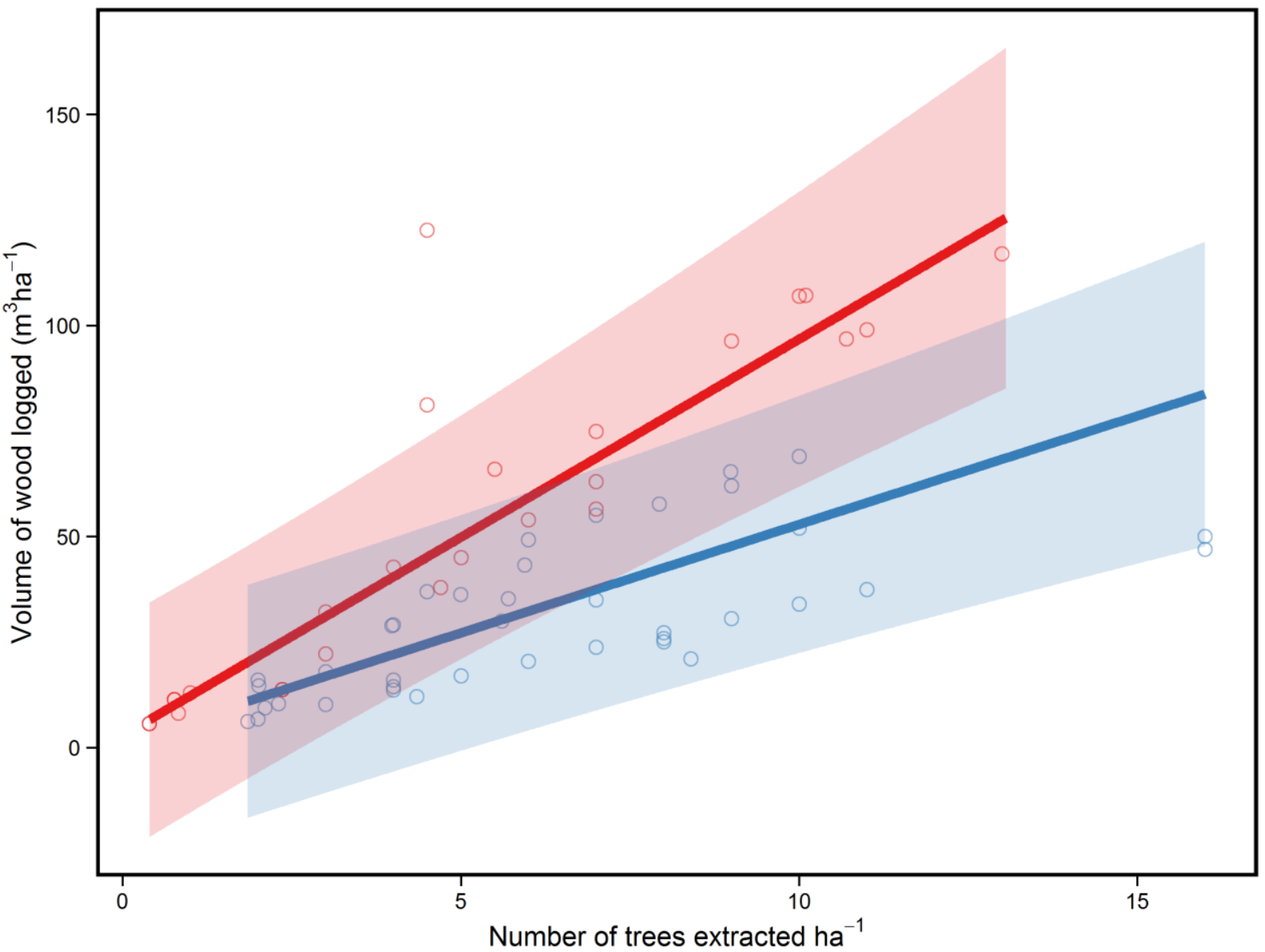

679 Figure 2 - The relationship between the number of trees extracted $\mathrm{ha}^{-1}$ and the volume of wood

680 logged ha ${ }^{-1}$ for Asia and Africa (red) and the Americas (blue). Points represent individual sites, solid

681 lines the predictions from the most parsimonious mixed model with bands representing 95\%

682 confidence intervals of the coefficients.

683 


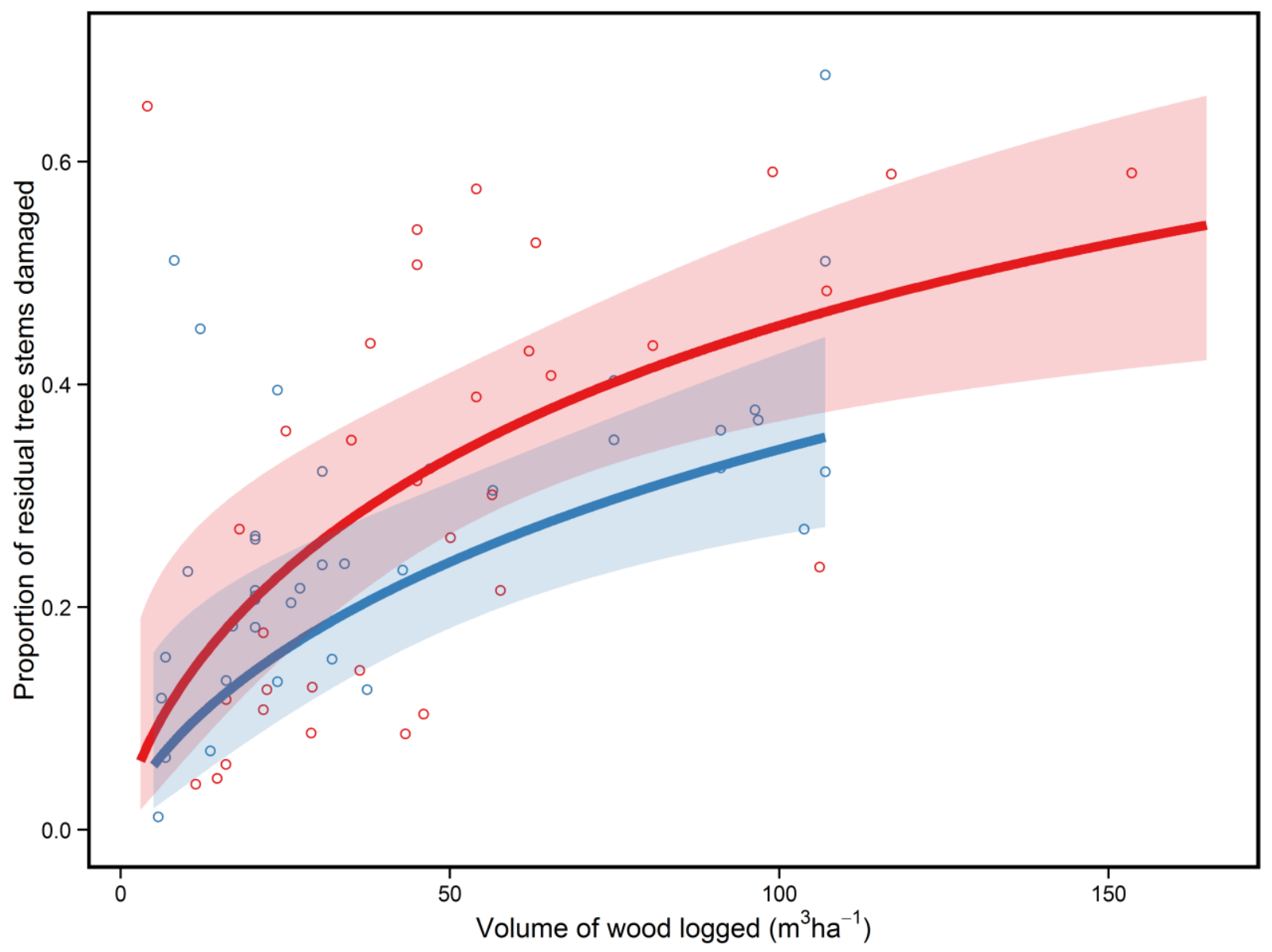

685 Figure 3 - Impact of selective logging intensity and logging technique on the proportion of residual 686 tree stems damaged in tropical forests $(n=72)$. Points represent single sites, solid lines are the 687 predictions the most parsimonious linear mixed effects model $\left(\mathrm{R}^{2}=0.27\right)$ and shaded areas represent 688 the $95 \%$ confidence intervals of these estimates. Red points and lines refer to sites where 689 conventional harvest methods were used and blue points and lines where RIL techniques were used. 690 For details of alternative models considered see Table 2. 


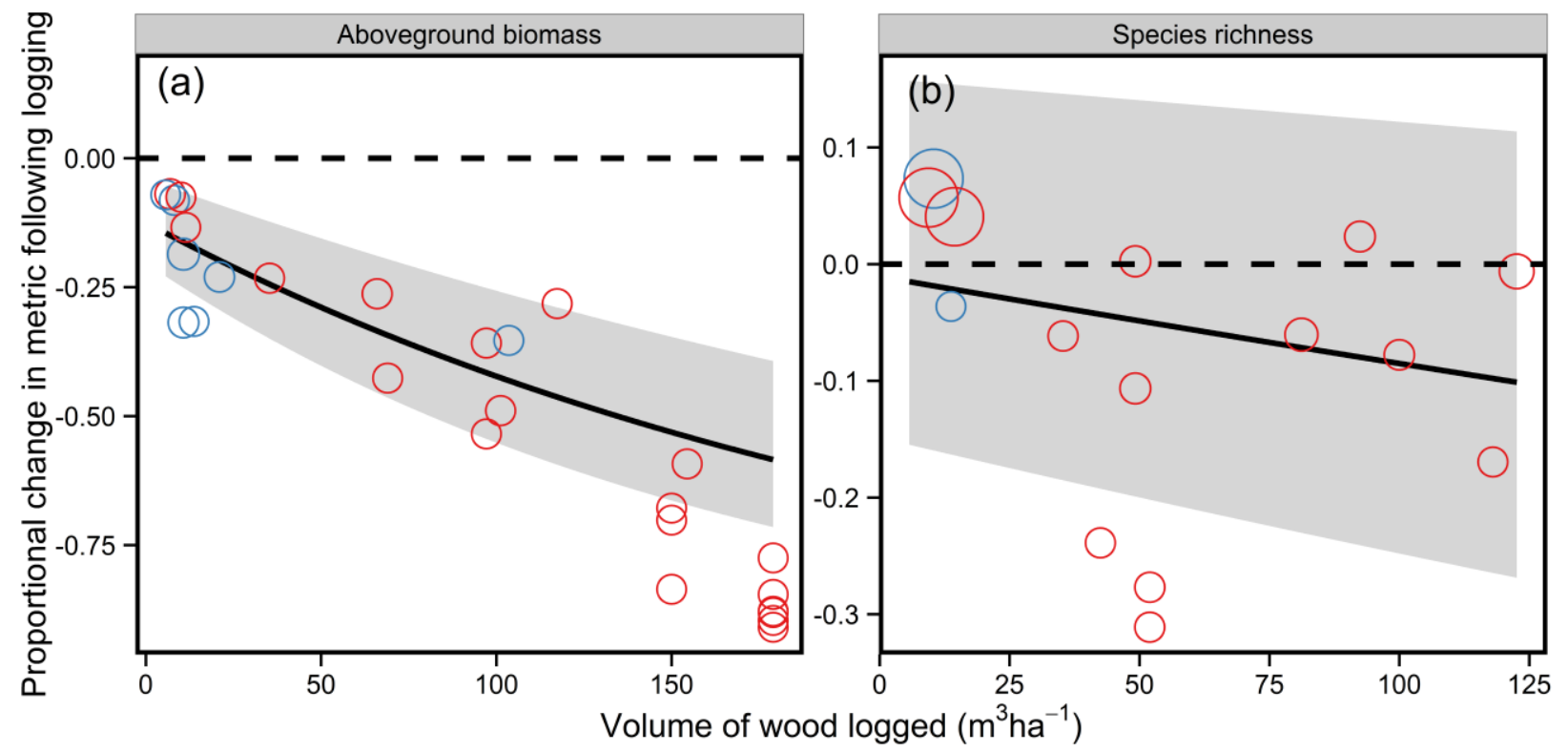

693 Figure 4 - Impacts of selective logging intensity on changes in (a) aboveground biomass ( $\mathrm{n}=32)$ and

694 (b) tree species richness. Blue symbols are those sites where reduced impact logging (RIL) was

695 carried out, red symbols correspond to conventionally logged sites with size indicative of study

696 weight. The solid lines represents the predictions from the weighted meta-regression models with

697 lowest and shaded area the corresponding 95\% confidence intervals. The horizontal dashed line

698 indicates when there is no difference between logged and unlogged sites. Note that RIL sites tend to

699 be logged at a lower intensity than conventionally logged sites. Alternative models considered are

700 detailed in Tables 3 and 4. 


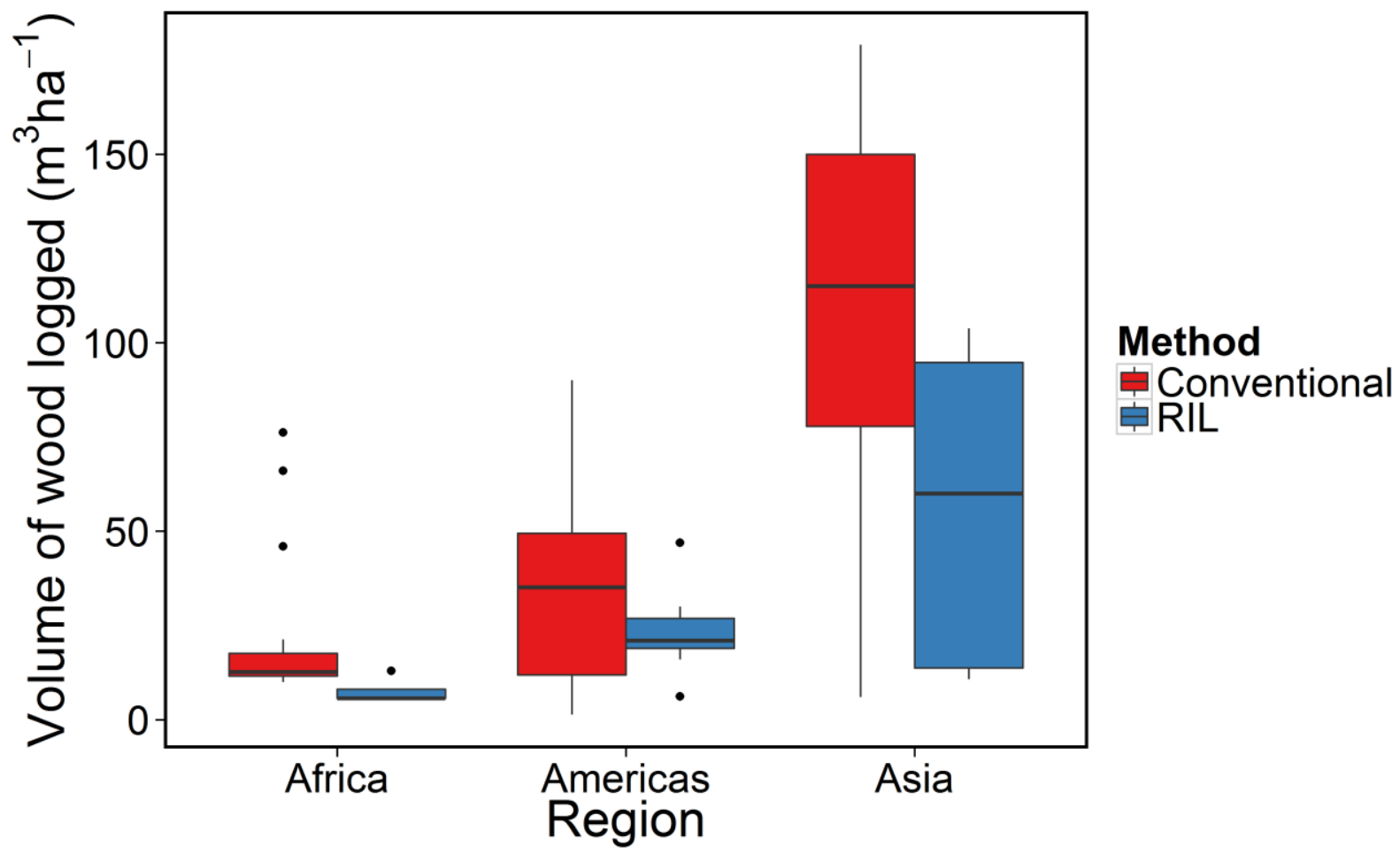

Figure 5 - Variation in logging intensity (measured as volume of wood extracted per hectare) by 706 region and logging method for all studies used in our meta-analyses. Note that conventional logging 707 tends to have higher logging intensity on all continents. 
710 Table 1 - Details of studies used for analyses of changes in aboveground biomass and tree species richness following selective logging in tropical 711 forests.

\begin{tabular}{|c|c|c|c|c|c|c|c|}
\hline Study & Variable & $\begin{array}{l}\text { Response } \\
\text { ratio }\end{array}$ & $\begin{array}{c}\text { Effect size } \\
\text { variance }\end{array}$ & $\begin{array}{c}\text { Volume logged } \\
\left(\mathrm{m}^{3} \mathrm{ha}^{-1}\right)\end{array}$ & $\begin{array}{c}\text { Time since logging } \\
\text { (years) }\end{array}$ & Method & Continent \\
\hline Berry et al., 2010 & AGB & -0.77 & 0.06 & 97.2 & 0 & Conventional & Asia \\
\hline Bryan et al., 2010 & AGB & -0.38 & 0.01 & 10.7 & 1 & RIL & Asia \\
\hline D’Oliveira et al., 2012 & AGB & -0.07 & 0.01 & 6.9 & 1 & Conventional & Americas \\
\hline Gerwing, 2002 & $A G B$ & -0.26 & 0.01 & 35.3 & 5 & Conventional & Americas \\
\hline Imai et al., 2012 & AGB & -0.38 & 0.05 & 13.74 & 8 & RIL & Asia \\
\hline Mazzei et al., 2010 & AGB & -0.26 & 0.00 & 21 & 0 & RIL & Americas \\
\hline \multirow{2}{*}{ Medjibe et al., 2011} & \multirow{2}{*}{ AGB } & -0.08 & 0.01 & 8.11 & 0 & RIL & Africa \\
\hline & & -0.08 & 0.01 & 8.11 & 0 & RIL & Africa \\
\hline Medjibe et al., 2013 & AGB & -0.07 & 0.05 & 5.7 & 0 & RIL & Africa \\
\hline \multirow{8}{*}{ Pfeifer et al., 2015} & \multirow{8}{*}{$A G B$} & -1.21 & 0.46 & 150 & 10 & Conventional & Asia \\
\hline & & -1.21 & 0.51 & 150 & 10 & Conventional & Asia \\
\hline & & -1.87 & 0.93 & 179 & 10 & Conventional & Asia \\
\hline & & -1.13 & 0.40 & 150 & 10 & Conventional & Asia \\
\hline & & -2.40 & 2.60 & 179 & 10 & Conventional & Asia \\
\hline & & -2.13 & 1.53 & 179 & 10 & Conventional & Asia \\
\hline & & -2.26 & 1.99 & 179 & 10 & Conventional & Asia \\
\hline & & -2.11 & 1.46 & 179 & 10 & Conventional & Asia \\
\hline
\end{tabular}


Table 1 continued

\begin{tabular}{|c|c|c|c|c|c|c|c|}
\hline \multirow{2}{*}{ Pinard and Putz, 1996} & \multirow[t]{2}{*}{$A G B$} & -0.90 & 0.03 & 154 & 0 & \multirow{2}{*}{$\begin{array}{c}\text { Conventional } \\
\text { RIL }\end{array}$} & \multirow{2}{*}{$\begin{array}{l}\text { Asia } \\
\text { Asia }\end{array}$} \\
\hline & & -0.44 & 0.02 & 103 & 0 & & \\
\hline Rockwell et al., 2014 & AGB & -0.08 & 0.03 & 10 & 1 & Conventional & Americas \\
\hline Saner et al., 2012 & $A G B$ & -0.33 & 0.03 & 117.38 & 0 & Conventional & Asia \\
\hline Tangki and Chappell, 2008 & AGB & -0.67 & 0.01 & 101.2 & 11 & Conventional & Asia \\
\hline Baraloto et al., 2012 & Richness & 0.0082 & 0.0032 & 55 & 20 & Conventional & Americas \\
\hline Berry et al., 2008 & Richness & 0.0636 & 0.0013 & 92.4 & 18 & Conventional & Asia \\
\hline Burghouts et al., 1994 & Richness & -0.0808 & 0.0033 & 100 & 12 & Conventional & Asia \\
\hline \multirow{2}{*}{ Cannon et al., 1998} & \multirow[t]{2}{*}{ Richness } & -0.3727 & 0.0059 & 52 & 1 & Conventional & Asia \\
\hline & & -0.2730 & 0.0064 & 42.5 & 8 & Conventional & Asia \\
\hline \multirow{3}{*}{ Carreño-Rocabado et al., 2012} & \multirow{3}{*}{ Richness } & 0.0706 & 0.0001 & 10.4 & 0 & RIL & Americas \\
\hline & & 0.0554 & 0.0001 & 9.4 & 0 & Conventional & Americas \\
\hline & & 0.0398 & 0.0001 & 14.4 & 0 & Conventional & Americas \\
\hline Foody and Cutler, 2003 & Richness & -0.1858 & 0.0139 & 118 & 10 & Conventional & Asia \\
\hline \multirow{2}{*}{ Gerwing, 2002} & \multirow{2}{*}{ Richness } & -0.0635 & 0.0052 & 35.3 & 5 & Conventional & Americas \\
\hline & & -0.3242 & 0.0044 & 52 & 5 & Conventional & Americas \\
\hline \multirow{2}{*}{ Gourlet-Fleury et al., 2013a } & \multirow[t]{2}{*}{ Richness } & -0.0624 & 0.0009 & 81.16 & 24 & Conventional & Africa \\
\hline & & -0.0062 & 0.0006 & 122.57 & 24 & Conventional & Africa \\
\hline Imai et al., 2012 & Richness & -0.0370 & 0.0295 & 13.74 & 9 & RIL & Asia \\
\hline Villela et al., 2006 & Richness & 0.1178 & 0.0340 & 90 & 5 & Conventional & Americas \\
\hline \multirow{2}{*}{ Webb and Peralta, 1998} & \multirow{2}{*}{ Richness } & 0.0024 & 0.0022 & 49.2 & 1 & RIL & Americas \\
\hline & & -0.1127 & 0.0020 & 49.2 & 0 & RIL & Americas \\
\hline \multirow{2}{*}{ Cazzolla Gatti et al., 2014} & \multirow{2}{*}{ Richness } & -0.1575 & 0.0485 & 100 & 15.09615 & Conventional & Africa \\
\hline & & -0.7080 & 0.0372 & 100 & 15.09615 & Conventional & Africa \\
\hline
\end{tabular}


713 Table 2 - Rank of different models considered for the description of residual stand damage

714 following selective logging in tropical forests. Models are ranked by median AICc.

715

\begin{tabular}{|c|c|c|c|c|c|c|}
\hline Variables & $\begin{array}{l}\text { Degrees } \\
\text { of } \\
\text { freedom }\end{array}$ & $\begin{array}{l}\text { Log } \\
\text { Liklihood }\end{array}$ & AICc & $\Delta \mathrm{AIC}$ & $\begin{array}{l}\text { AICc } \\
\text { weight }\end{array}$ & $\begin{array}{l}\text { Marginal } \\
\mathbf{R}^{2}\end{array}$ \\
\hline $\log ($ Volume $)+$ & 7 & -67.62 & 150.99 & 0.00 & 0.72 & 0.33 \\
\hline \multicolumn{7}{|l|}{ Method } \\
\hline $\log ($ Volume $)$ & 6 & -70.27 & 153.82 & 2.83 & 0.17 & 0.29 \\
\hline $\log ($ Volume $) *$ Method & 8 & -68.28 & 154.84 & 3.85 & 0.10 & 0.32 \\
\hline Method & 6 & -74.15 & 161.59 & 10.59 & 0.00 & 0.05 \\
\hline Volume+ Method & 7 & -73.91 & 163.57 & 12.58 & 0.00 & 0.28 \\
\hline Volume & 6 & -77.76 & 168.81 & 17.82 & 0.00 & 0.23 \\
\hline Volume*Method & 8 & -78.06 & 174.40 & 23.40 & 0.00 & 0.30 \\
\hline Null model & 3 & -86.68 & 179.71 & 28.72 & 0.00 & 0.00 \\
\hline
\end{tabular}

716

717 
718 Table 3 - Rank of different models considered for description of post-logging changes in

719 aboveground biomass. Models are ranked by their median AICc so that the top model is that which

720 tended to be considered most parsimonious across bootstrap iterations. $\pi_{\mathrm{i}}$ refers to the proportion of

721 bootstrap iterations in which an individual model was selected as most parsimonious following

722 Gibson et al. (2011).

\begin{tabular}{|c|c|c|c|c|c|c|}
\hline Model variables & $\begin{array}{l}\text { Model } \\
\text { rank }\end{array}$ & $\boldsymbol{\pi}_{\mathbf{i}}$ & $\begin{array}{c}\text { Log } \\
\text { likelihood }\end{array}$ & AICc & $\Delta \mathrm{AICc}$ & $\begin{array}{c}\text { Pseudo- } \\
\mathbf{R}^{\mathbf{2}}\end{array}$ \\
\hline Volume & 1.0 & 1.00 & 5.21 & 0.90 & 0.00 & 0.43 \\
\hline Volume*Method+Volume ${ }^{2}$ & 2.0 & 0.00 & 8.37 & 3.66 & 2.79 & 0.58 \\
\hline Volume*Method & 3.0 & 0.00 & 8.34 & 3.73 & 2.86 & 0.58 \\
\hline Voume+Volume ${ }^{2}$ & 4.0 & 0.00 & 5.32 & 4.81 & 3.63 & 0.44 \\
\hline Volume*Age & 5.0 & 0.00 & 6.02 & 8.36 & 7.17 & 0.48 \\
\hline Volume*Age+Volume*Method & 6.0 & 0.00 & 9.69 & 14.62 & 13.18 & 0.64 \\
\hline Age & 7.0 & 0.00 & -2.36 & 16.05 & 15.15 & 0.09 \\
\hline Null & 8.0 & 0.00 & -4.33 & 16.51 & 15.80 & 0.00 \\
\hline Method & 10.0 & 0.00 & -2.88 & 17.09 & 16.27 & 0.06 \\
\hline Volume* Method+Volume^2 ${ }^{*}$ Method & 10.0 & 0.00 & 8.41 & 17.19 & 16.32 & 0.58 \\
\hline
\end{tabular}


725 Table 4 - Rank of different models considered for description of post-logging changes in tree

726 species richness. Models are ranked by their median AICc so that the top model is that which tended

727 to be considered most parsimonious across bootstrap iterations. $\pi$ i refers to the proportion of

728 bootstrap iterations in which an individual model was selected as most parsimonious following

729 Gibson et al. (2011).

\begin{tabular}{lllllll}
\hline Model variables & $\begin{array}{l}\text { Model } \\
\text { rank }\end{array}$ & $\boldsymbol{\pi i}$ & $\begin{array}{l}\text { Log } \\
\text { likelihood }\end{array}$ & AICc & $\Delta$ AICc & \multicolumn{2}{c}{ Pseudo- } \\
& \multicolumn{3}{c}{$\mathbf{R}^{2}$} \\
\hline Volume & 1 & 0.42 & -6.60 & 5.20 & 0.00 & 0.30 \\
Age & 2 & 0.00 & -7.88 & 7.76 & 2.56 & 0.19 \\
Method & 3 & 0.34 & -9.62 & 11.24 & 3.48 & 0.00 \\
Null & 4 & 0.25 & -12.76 & 17.51 & 6.28 & 0.00 \\
\hline
\end{tabular}

730 